\title{
INFECÇÃO EXPERIMENTAL PELO VÍRUS VACCINIA EM EQUINOS
}

CLÁUDIO HENRIQUE GONÇALVES BARBOSA

DISSERTAÇÃO DE MESTRADO

EM SAÚDE ANIMAL

BRASÍLIA/DF 


\section{INFECÇÃO EXPERIMENTAL PELO VÍRUS VACCINIA EM EQUINOS}

CLÁUDIO HENRIQUE GONÇALVES BARBOSA

ORIENTADOR: PROF. DR. JANILDO LUDOLF REIS JUNIOR

DISSERTAÇÃO DE MESTRADO EM SAÚDE ANIMAL ÁREA DE CONCENTRAÇÃO: MEDICINA PREVENTIVA E PATOLOGIA VETERINÁRIA

LINHA DE PESQUISA: PATOLOGIA VETERINÁRIA

PUBLICAÇÃO: 105/2015

BRASÍLIA/DF

2015 
UNIVERSIDADE DE BRASÍLIA

\title{
INFECÇÃO EXPERIMENTAL PELO VÍRUS
}

\author{
VACCINIA EM EQUINOS
}

\section{CLÁUDIO HENRIQUE GONÇALVES BARBOSA}

DISSERTAÇÃO DE MESTRADO SUBMETIDA AO PROGRAMA DE PÓS-GRADUAÇÃO EM SAÚDE ANIMAL, COMO PARTE DOS REQUISITOS NECESSÁRIOS À OBTENÇÃO DO GRAU DE MESTRE EM SAÚDE ANIMAL.

APROVADA POR:
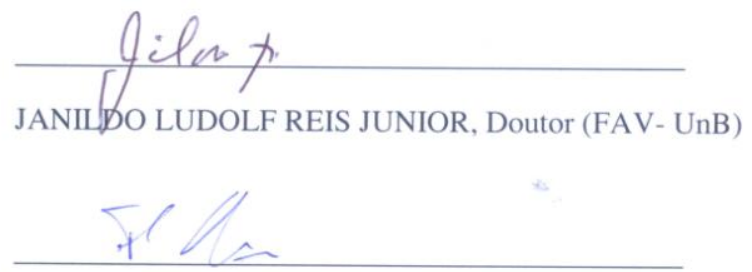

FABIANO JOSÉ F. SANT'ANA, Doutor (FAV- UnB)

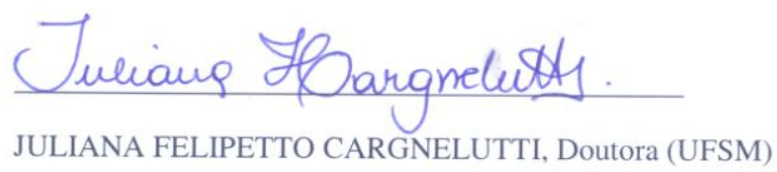

BRASÍLIA/DF, 06 de 02 de 2015 


\section{REFERÊNCIA BIBLIOGRÁFICA E CATALOGAÇÃO}

BARBOSA, C. H. G. Infecção experimental pelo vírus Vaccinia em equinos. Brasília: Faculdade de Agronomia e Medicina Veterinária, Universidade de Brasília, 2015, 42 p. Dissertação de Mestrado.

Documento formal, autorizando reprodução desta dissertação de Mestrado para empréstimo ou comercialização, exclusivamente para fins acadêmicos; foi passado pelo autor à Universidade de Brasília e achase arquivado na secretaria do Programa. O autor reserva para si os outros direitos autorais, de publicação. Nenhuma parte desta dissertação de mestrado pode ser reproduzida sem a autorização por escrito do autor. Citações são estimuladas, desde que citada a fonte.

Barbosa, Cláudio Henrique Gonçalves

Infecção experimental pelo vírus Vaccinia em equinos / Cláudio Henrique Gonçalves Barbosa

Orientação de Janildo Ludolf Reis Junior.

Brasília, 2015. 42p.: il.

Dissertação de mestrado (M) - Universidade de Brasília / Faculdade de Agronomia e Medicina Veterinária, 2015.

1. Vírus Vaccinia. 2. Infecção. 3. Equinos. 4. vaccínia bovina. I. BARBOSA, C.H.G. II. Título

Agris / FAO 
“Os lábios da Sabedoria estão fechados, exceto aos ouvidos do Entendimento"

(O CAIBALION) 
Dedico este trabalho ao meu avôhai, Fânor Gonçalves Cruzeiro e as mulheres da minha vida: minhas mães Odete Pereira Gonçalves e Cleuza Aparecida Gonçalves e, minha irmãzinha Tatiane Furtado de Carvalho. 


\section{AGRADECIMENTOS}

Agradeço primeiramente ao Pai Celestial que me deu coragem para enfrentar essa jornada, força para ultrapassar os obstáculos e sabedoria em minhas decisões. À Nossa Senhora, mãe de todos nós por ter sido fonte de consolo nos momentos de tristeza e solidão. Ao nosso padroeiro São Francisco de Assis por me mostrar que, mesmo que a nossa fé nos homens esteja abalada, devemos sempre pensar no bem maior para os animais.

Agradeço à minha mãe e grande amiga, a quem dedico este trabalho, por nunca ter me permitido desistir e por ser sempre meu porto seguro, para o qual posso sempre voltar.

Agradeço aos meus pais e mentores: prof. Humerto 'Marfim' Coelho e Hélio ‘Ébano’ Alberto, que mesmo longe nunca me negaram um conselho ou uma palavra amiga, e a toda a minha família do Laboratório de Patologia Animal da UNIUBE.

Agradeço à minha irmãzinha Tatiane Furtado de Carvalho, a quem também dedico essa dissertação, pela força e por muitas e muitas horas de conversas ao telefone.

Agradeço a todos os meus irmãos e a Ordem DeMolay, pois sem os seus ensinamentos hoje eu não seria o homem que sou. Um Grande e Fraternal Abraço.

Agradeço aos professores Janildo Ludolf Reis Junior e Fabiano José F. de Sant'Ana pela orientação e paciência nesses dois anos de estada na UnB. Muito Obrigado!

Agradeço à equipe de alunos e técnicos do Laboratório de Patologia Veterinária da Universidade de Brasília: Saulo, Guilherme, Lorena, Letícia, Anahí, Lícia, Lili, Tainã, Rosália e, em especial, a Susy que me mostrou que os trabalhos metódicos e repetitivos podem ser monótonos mas de fácil execução. Muito Obrigado!

Agradeço a todos os professores e funcionários do Programa de Pós-graduação em Saúde Animal da UnB (PPGSA-UnB) pela oportunidade de estar aqui. Muito Obrigado! 
Agradeço aos meus amigos Edinho, Flávio Veloso e Felipe Borges pelos conselhos e momentos agradáveis.

Agradeço à toda equipe do Hospital Veterinário de Grandes Animais, 'HVetão', em especial aos colegas Vitão, Sarinha, Leo, Cleyber, Juliana, Renan Fiel, André Diogo, Diego, Flavinha e Rosana pela 'mãozinha' na lida com os cavalos. E também aos professores José Renato e Antônio Rafael.

Agradeço ao Regimento de Policia Montada do Distrito Federal (RPMom-DF) na figura do colega Augusto Moscardini, por ter cedido os animais para a execução desse trabalho.

Agradeço à equipe do Setor de Virologia da Universidade Federal de Santa MariaUFSM, em especial aos prof. Eduardo Furtado Flores e Juliana Felipetto Cargnelutti, por terem cedido as amostras e realizado os exames de PCR e soroneutralização das amostras virais.

Agradeço à Coordenação de Aperfeiçoamento de Pessoal de Nível Superior (CAPES) pelo apoio financeiro sem o qual não poderia concluir, quiçá, começar essa empresa.

Agradeço a todos aqueles que, direta ou indiretamente, me ajudaram e apoiaram nessa fase impar da minha vida. Muito Obrigado a todos e a cada um!

Non nobis Domine, non nobis. Sed nomine tuo ad gloriam. 
RESUMO - O vírus Vaccina (VACV) é o agente etiológico da vaccínia bovina, doença zoonótica re-emergente e de grande importância socioeconômica. Raros são os relatos de VACV em equinos no Brasil, um dos mais recentes data de 2008 no município de PelotasRS, no qual duas cepas, Pelotas Vírus 1 e Pelotas Vírus 2 (P1V e P2V), acometeram 14 animais. Essas cepas foram inoculadas em equinos com o objetivo de verificar se há o desenvolvimento da infecção, assim como de lesões macro e microscópicas. Para tanto, seis equinos adultos e sadios foram inoculados via escarificação do plano nasolabial e foram acompanhados durante 28 dias pós inoculação (d.p.i.). Os animais desenvolveram lesões macroscópicas compatíveis com aquelas causadas pelo vírus Vaccinia no período compreendido entre dois e oito d.p.i.; análises dos fragmentos de tecidos coletados apresentaram acantose, degeneração balonosa de queratinócitos, úlceras e infecção bacteriana secundária. Inclusões eosinofílicas intracitoplasmáticas foram infrequentemente observadas em queratinócitos degenerados ao redor das áreas de necrose. Apenas um animal apresentou excreção viral nos locais de inoculação confirmada via PCR. Os resultados obtidos neste estudo demonstram que a inoculação das cepas P1V e P2V resultam em infecção e no desenvolvimento, ainda que brandas, de lesões macro e microscópicas. Estes achados sugerem que equinos apresentam baixa susceptibilidade ao $\mathrm{VACV}$, especialmente às cepas P1V e P2V, e possivelmente representam baixo potencial transmissor do vírus para outras espécies. Portanto, estudos adicionais são necessários para avaliar o potencial de equinos na disseminação e/ou manutenção destas cepas do vírus Vaccinia em equinos, bovinos e no homem.

PALAVRAS CHAVE: Vírus Vaccinia; Infecção; Equinos; vaccínia bovina. 
ABSTRACT- Vaccinia virus (VACV) is the etiologic agent of bovine vaccinia, a zoonotic reemerging disease of high socioeconomic impact. There are few reports of VACV in horses in Brazil. The most recent was described in the city of Pelotas in 2008, where two strains, Pelotas Virus 1 and Pelotas Virus 2 (P1V and P2V), infected 14 animals. These strains were inoculated in horses in order to verify whether experimental inoculation results in infection, and gross and microscopic lesion development. Therefore, 6 adult healthy horses were inoculated via scarification of nasolabial surface. These animals were daily examined for 28 days post inoculation (d.p.i.). Gross lesions consistent with those caused by vaccinia virus were observed between 2 and 8 dpi. Microscopically there were epidermal hyperplasia (acanthosis), ballooning degeneration of the stratum spinosum, necrosis and loss of the epidermis, with intralesional bacteria. Moderate infiltration of neutrophils, macrophages and lymphocytes were observed in the superficial dermis. Intracytoplasmic eosinophilic inclusions were infrequently observed in degenerate keratinocytes from adjacent necrotic areas. Only one animal had viral excretion from the inoculation site, confirmed by PCR. The results of this study demonstrate that the inoculation of P1V and P2V strains result in infection, although mild, with macro and microscopic lesion development. These findings suggest that horses have low susceptibility to VACV, especially to P1V and P2V strains, and possibly represent low potential to transmit the virus to other species, especially dairy cattle. Therefore, additional studies are needed to evaluate the potential of horses in the dissemination and/or maintenance of these strains of vaccinia virus in cattle, horses, and in humans.

KEYWORDS: Vaccinia virus; infection; horses; bovine vaccina. 


\section{LISTA DE FIGURAS}

Figura 1- Evolução cronológica das lesões macroscópicas de equino infectado experimentalmente com vírus Vaccinia.

Figura 2- Pele (região nasolabial esquerdo) equino C2V2 infectado experimentalmente pelo vírus Vaccinia. .20 


\section{LISTA DE TABELAS}

Tabela 1: Distribuição temporal de lesões macroscópicas em equinos infectados experimentalmente pelo vírus Vaccinia e no animal controle (0 a 12 dpi) 16

Tabela 2: Resultados dos testes de sorologia via Soroneutralização, Excreção Viral e PCR, de acordo com dia pós inoculação e equinos infectados experimentalmente pelo vírus Vaccinia. 


\section{SUMÁRIO}

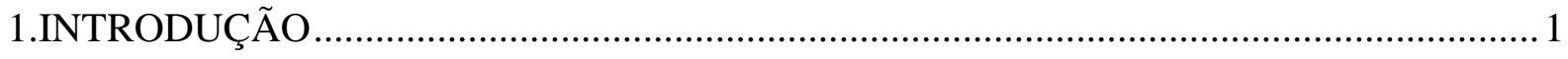

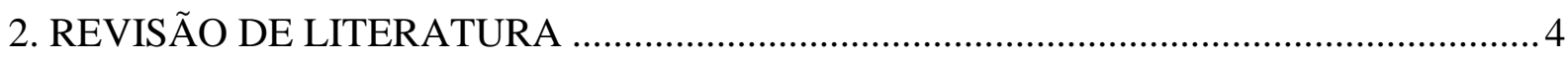

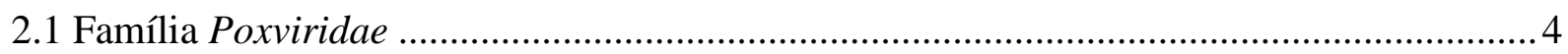

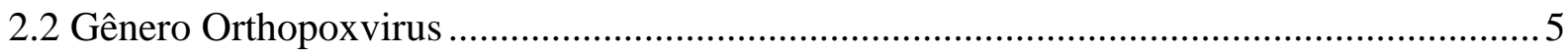

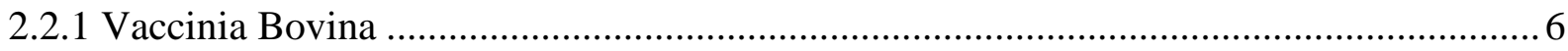

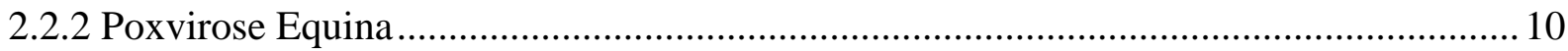

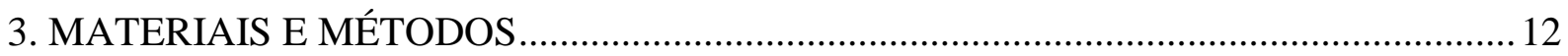

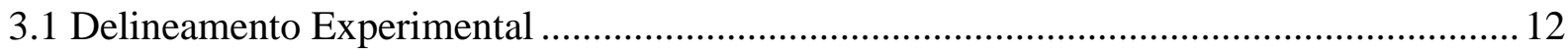

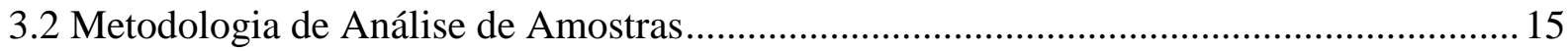

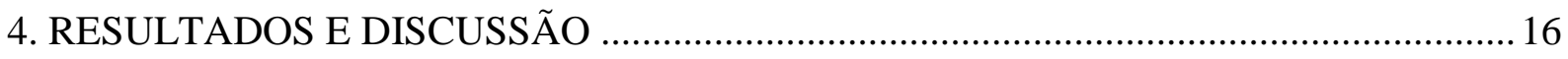

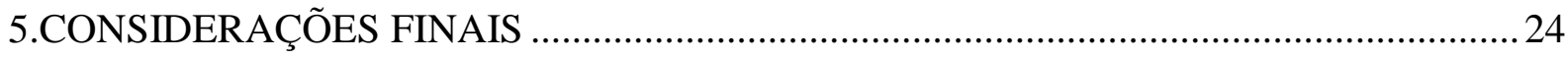

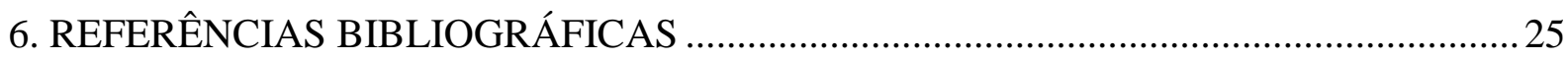

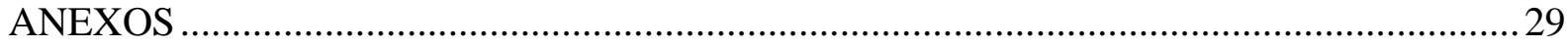




\section{INTRODUÇÃO}

O vírus Vaccinia (VACV), protótipo da família Poxviridae e pertencente ao gênero Orthopoxivirus, é reconhecidamente o agente etiológico da vaccínia bovina ou varíola bovina, uma doença zoonótica re-emergente e de grande importância socioeconômica, caracterizada por lesões proliferativas, vesiculo-pustulares e crostrosas no úbere e tetas de vacas ou no focinho e cavidade oral de bezerros em aleitamento (DELHON et al., 2006). No homem, mais frequentemente em ordenhadores, a infecção é semelhante àquela observada nos rebanhos, com lesões nas mãos e antebraços ou de forma disseminada por toda a face, olhos e orelhas (ESSBAUER et al., 2010).

Os prejuízos socioeconômicos associados a vaccínia bovina são expressivos, alguns autores relatam que a queda na produção de leite pode variar de 30 a $50 \%$ dependendo da quantidade de animais infectados. Somadas essas perdas aos custos com tratamento e afastamento produtivo dos animais, bem como a licença remunerada dos trabalhadores, a doença desencadeia uma quebra na cadeia produtiva do leite e grande perda econômica para o país (LEITE et al., 2005; LUDOULFO DE OLIVEIRA et al., 2010).

Historicamente diferentes orthopoxvírus de origem humana e animal estão associados à doença cutânea proliferativa. Os equinos parecem servir como hospedeiro alternativo para muitos poxvírus animais e humanos e, desenvolvem síndromes clínicas diferentes de acordo com a infecção causada por determinado vírus. Infecções por orthopoxvirus em equinos, em especial o Horsepox vírus (HSPV), causador da varíola equina, foram frequentemente 
descritas no século XIX e no começo do século XX, e se tornaram progressivamente raras até o ponto de serem consideradas extintas (BRUM et al., 2010; ESPARZA, 2013).

Infecções naturais por VACV em equinos são raras (KAMINJOLO JR. et al., 1974). Um dos relatos mais recentes no Brasil ocorreu em 2008 no município de Pelotas- RS (BRUM et al., 2010). Nesse surto, 14 equinos crioulos de uma mesma propriedade apresentaram a infecção dos quais: nove eram éguas lactantes, quatro potros e, um macho adulto castrado. Os autores citam que não havia outras espécies domésticas no mesmo pasto. Uma égua apresentou o focinho coberto por cicatrizes cujo curso clínico foi de 8 a 12 dias, sem qualquer outro sinal clínico. Progressivamente outros dez animais começaram a apresentar pápulas de 2-3 mm de diâmetro no focinho e narinas, nas faces mucosa e cutânea dos lábios. Havia ainda secreção serosa que fluía a partir do focinho e deixava um rastro de crostas. As lesões eram proliferativas e ulcerativas com aspecto verrucoso e se desprendiam ao serem manuseadas. As áreas afetadas foram tradadas com polivinilpirrolidona de iodo (PVPI) e culminaram com o fim das lesões deixando apenas áreas despigmentadas.

CAMPOS et al. (2010) realizaram o isolamento viral de dois equinos do surto descrito por BRUM et al. (2010). Por meio de técnicas de extração e purificação viral, verificou-se que em um dos animais infectados havia duas cepas distintas do vírus Vaccinia (denominados Pelotas vírus 1 - P1V, e Pelotas vírus 2- P2V) que variavam geneticamente em cerca de 5\% dos genes analisados. TRINDADE et al. (2006) também isolaram duas cepas diferentes em um surto de infecção VACV em bovinos, em Guarani-MG. Esses achados demonstram que é possível haver coinfecção viral em surtos de Vaccinia no Brasil.

Não existem estudos com a infecção experimental que utilizou as cepas P1V e P2V em equinos no Brasil. O único trabalho encontrado na literatura que avaliava a infecção pelo vírus Vaccinia nessa espécie foi realizado na Austrália (STUDDERT, 1989). Desta forma, é 
fundamental a realização de estudos com a infecção experimental com o VACV em equinos no Brasil, especialmente pelo fato de que grande parte das propriedades leiteiras do país utilizam equinos como ferramenta para o manejo do gado.

Para tanto, alíquotas dos vírus P1V e P2V foram gentilmente cedidas pelo Professor Eduardo Furtado Flores (Setor de Virologia da UFSM-RS), para que avaliação das características anatomopatológicas da infecção provocada por estas cepas em equinos sadios. Todos os procedimentos que envolveram o uso de animais foram aprovados pela Comissão de Ética no Uso Animal da Universidade de Brasília (CEUA-UnB) sob o número UnBDOC n ${ }^{\circ}$ $117983 / 2014$ (ver anexo 1).

O presente estudo pretendeu verificar se o vírus Vaccinia era capaz de infectar equinos sadios após inoculação experimental, via escarificação do plano nasolabial, com as cepas P1V e P2V. Além disso, foi realizada avaliação da cinética de desenvolvimento de lesões macro e microscópicas e a excreção de partículas virais nas secreções dos locais de inoculação. 


\section{REVISÃO DE LITERATURA}

O nome do vírus VACV é oriundo do termo vaccine (vacina, em Português), que é derivado do latim vacca (vaca, em Português). O pesquisador Edward Jenner, em 1798, inoculou em seres humanos pequena quantidade de material extraído de lesões de vacas com varíola bovina, o que resultava em lesões semelhantes às do vírus Cowpox e tornavam essas pessoas protegidas contra a varíola humana. Posteriormente, em 1881, Louis Pasteur propôs que o termo vacinação deveria ser aplicado a qualquer inoculação preventiva para doenças humanas e animais (ESSBAUER et al., 2010; ESPARZA, 2013).

\subsection{FAMÍLIA POXVIRIDAE}

Os membros da família Poxviridae têm importância tanto para os estudos de imunologia e de vacinas como também valor histórico, pois os agentes da varíola humana e bovina foram os primeiros vírus mais intensivamente estudados (FLORES, 2007).

De acordo com DAMON (2007), citado por CAMPOS et al. (2010), a família Poxviridae compreende um grande e complexo grupo de vírus DNA que podem infectar uma vasta gama de animais, por isso essa família é dividida em duas subfamílias: Entomopoxvirinae, cujos membros infectam invertebrados, e os Chordopoxvirinae que infectam vertebrados. As principais características dos membros dessa família são seus vírions grandes e complexos que contêm diversas enzimas para síntese e modificação de mRNAs; seu genoma é formado por uma molécula de DNA fita dupla e sua replicação ocorre inteiramente no citoplasma da célula hospedeira (FLORES, 2007). 
O VACV é considerado o protótipo para essa família devido à grande similaridade das bases de nucleotídeos de seu genoma com todos os poxvírus, além de sua importância histórica nos estudos de imunologia e de vacinas (FLORES, 2007).

\subsection{GÊNERO ORTHOPOXVIRUS}

O gênero Orthopoxvirus (OPV) é o de maior importância do ponto de vista humano e veterinário e engloba o vírus Variola (VARV) que infecta humanos, mundialmente erradicado em 1979; vírus Vaccinia (VACV) que infecta búfalos, bovinos, humanos, suínos e lagomorfos com distribuição mundial; o vírus Cowpox (CPXV) que infecta carnívoros, bovinos, humanos e roedores e só é encontrado na Europa e Rússia (FLORES, 2007).

Os OPVs contém de 170 a 230 genes em seu DNA, com cerca de 130-375 kbp. As regiões centrais de seu genoma, de aproximadamente 100 kbp, estão relacionadas à replicação intracitoplasmática e são altamente conservados entre as espécies do gênero (ESSBAUER et al., 2010). Já as regiões terminais codificam genes envolvidos na interação vírus-hospedeiro, principalmente na resposta imunológica do hospedeiro (DELHON et al., 2006). A variabilidade genética das regiões terminais contribui para a ampliação da gama de hospedeiros e para a virulência dos OPVs, o que aumenta a capacidade patogênica dos vírus (FLORES, 2007).

Os OPVs são indistinguíveis morfologicamente entre si; sua replicação produz partículas que se aglutinam e são visíveis em microscopia óptica, denominados corpúsculos de inclusão intracitoplasmáticos (FLORES, 2007).

Muito pouco se sabe sobre a manutenção natural das orthopoxviroses. Diferentes espécies de roedores selvagens são apontadas como reservatórios naturais de CPXV na GrãBretanha e outros países da Europa onde o vírus é endêmico. Esta informação é compatível 
com situação epidemiológica das ortopoxviroses no Brasil, embora tenham sido relatados alguns casos recentes de infecção por VACV, pouco se sabe sobre sua ocorrência e circulação no país (BAXBY, 1977; TRINDADE et al., 2004).

Devido às semelhanças genéticas de cerca de $75 \%$ do genoma entre as espécies e, sua relação antigênica, os OPVs conferem reação imunológica cruzada. Em outras palavras, após a infecção por algum OPV, o animal desenvolve proteção contra os outros membros do gênero (ESSBAUER et al., 2010).

O VACV foi utilizado como modelo para a produção de vacinas para a varíola humana se deve à sua baixa virulência para o homem e à sua grande semelhança antigênica com o VARV (BAXBY, 1977). O último caso de varíola humana ocorreu na Somália, em 1977, e a doença foi considerada erradicada pela Organização Mundial de Saúde (OMS) em 1980 (SILVA et al., 2008; SILVA-FERNANDES et al., 2009).

Embora as medidas adotadas pela OMS tenham solucionado um mal que assolava a população mundial, elas trouxeram graves consequências. Com o fim das vacinações o título de anticorpos contra os OPVs caiu na população humana, o que permitiu a ocorrência de surtos de vaccínia bovina, varíola bovina, monkeypoxvirose e outras orthopoxviroses na população humana (SILVA-FERNANDES et al., 2009).

\subsubsection{Vaccinia bovina}

A varíola bovina verdadeira é uma enfermidade causada pelo Cowpox vírus e só é encontrado na Europa e Oriente Médio (SILVA et al., 2008). Popularmente, no Brasil, denomina-se a vaccínia bovina como "varíola bovina" devido à semelhança entre as lesões provocadas pelos agentes. A vaccína bovina é uma zoonose re-emergente causada pela infecção com o VACV, e têm sido descrita em vários surtos no Brasil (LOBATO et al., 2005; 
SANT'ANA et al., 2013). As infecções são consideradas de grande impacto na saúde pública e são frequentemente relatadas entre trabalhadores rurais, com destaque para os ordenhadores.

SILVA et al. (2008) descreveram três casos humanos ocorridos na primavera de 2007, em Itajubá- MG. Já SILVA-FERNANDES et al. (2009) relataram um surto de vaccínia bovina no estado do Rio de Janeiro no período de 2002 a 2006, no qual 52\% das pessoas afetadas apresentaram sinais clínicos da doença, dos quais $57,4 \%$ foram causados pelo VACV; outro fato importante a ser considerado é que, de acordo com os últimos autores, metade dos pacientes do estudo foram vacinados durante a Campanha Nacional de Erradicação da Varíola.

TRINDADE et al. (2006), em um estudo epidemiológico com 72 propriedades, durante um surto de vaccínia bovina na cidade de Guarani - $\mathrm{MG}$, relataram que foram encontradas 1020 vacas lactantes com lesões papulares que evoluíam para úlceras e que em $83 \%$ das propriedades foram encontradas pessoas com as mesmas lesões, totalizando 110 casos humanos sugestivos de varíola bovina. Os mesmos autores ainda descrevem a ocorrência de transmissão horizontal em seres humanos.

Os prejuízos causados pelos surtos de varíola bovina com tratamento e afastamento do trabalhador desencadeiam um déficit econômico e social na cadeia produtiva do leite o que afeta direta e indiretamente a bovinocultura nacional. LEITE et al. (2005), assim como LULDOULFO DE OLIVEIRA et al. (2012), apontaram ainda a redução na produção de leite, gastos com assistência veterinária e infecções secundárias da glândula mamária como danos diretos às bacias leiteiras do país. LOBATO et al. (2005), em um de seus estudos sobre varíola bovina, apontaram que a redução na produção de leite causada por essas infecções variaram de 30 a $50 \%$. 
Os trabalhadores infectam-se principalmente via contato direto das mãos com o exsudato proveniente das lesões nas tetas das vacas infectadas (ABRAHÃO et al., 2010), o que corrobora com os achados de LOBATO et al. (2005), os quais perceberam que as propriedades com ordenha mecanizada possuíam menor taxa de animais doentes o que sugere que o manejo de pré e pós dipping seja eficaz no extermínio de partículas virais infectantes e consequentemente levando a menor risco de infecção pelos ordenhadores. OLIVEIRA (2009) provou que o VACV é sensível à desinfecção com soluções de hipoclorito de sódio a 0,5\%.

Em seres humanos os primeiros sintomas da varíola bovina surgem entre cinco a sete dias pós infecção e são caracterizados por máculas pruriginosas nas áreas de contato seguida de febre (SILVA et al., 2008). A lesão progride e forma pústulas ulceradas que dão origem a áreas de necrose com formação de crostas que desaparecem em poucas semanas devido ao caráter autolimitante da doença. O curso médio da doença em humanos é de três a quatro semanas (TRINDADE et al., 2006) durante o qual há linfadenopatia (principalmente nas regiões axilares, submandibulares e inguinal), cefaleia, letargia e mialgia. Após nove dias do surgimento dos sintomas já podem ser detectados anticorpos contra OPVs. As lesões ocorrem geralmente nas mãos e antebraços, porém devido a replicação viral e o prurido, as partículas infectantes podem disseminar-se para os olhos, orelhas e narinas. Em seres humanos os diagnósticos diferenciais incluem impetigo bolhoso, erisipela, doença da arranhadura do gato e antrax (SILVA et al., 2008).

O controle é feito com isolamento da propriedade e nos pacientes acometidos são administradas drogas paliativas, antibioticoterapia e limpeza e debridamento das lesões. A severidade das infecções por poxvírus em humanos está associada ao estado imunológico do paciente bem como ao histórico de vacinação e a virulência do vírus. Coinfecções com outros 
poxvírus, a exemplo o Pseudocowpox já foram descritas além das infecções bacterianas secundárias (ABRAHÃO et al., 2010).

O curso clínico da doença nos animais domésticos é dividido em três fases. A fase aguda compreende os dias um a cinco depois do surgimento dos primeiros sinais da infecção (BRUM et al.,2010). As lesões iniciais se desenvolvem de forma proliferativa com aspecto verrucoso que tendem a se coalescer e tomar todo o focinho e plano nasal e face interna dos lábios. Ocasionalmente há secreção nasal serosa proveniente das narinas que escorre no sentido nasolabial e ao se secar originam novas lesões, uma vez que partículas infectantes estão presentes na secreção.

Durante o curso médio da doença em animais domésticos (cinco a oito dias) as lesões são mais raras e discretas e, são caracterizadas por crostas proliferativas e poucas vesículas, cujo desaparecimento dá origem a áreas despigmentadas. A partir de oito dias segue-se à última fase do curso clínico da doença cujas características são a recuperação progressiva das lesões, culminando com áreas despigmentadas e hiperqueratóticas (BRUM et al., 2010).

LUDOULFO DE OLIVEIRA et al. (2012) realizaram um estudo experimental com o VACV (nomeado GP2V) isolado a partir de um surto ocorrido em Guarani-MG, em 2006 com o objetivo de testar a viabilidade das partículas virais no leite e derivados. As amostras foram estocadas de acordo com a Normativa 5 do Ministério da Agricultura Pecuária e Abastecimento (MAPA) e simularam a condição real do leite produzido no país. Após tratamentos térmicos, que incluíam a pasteurização lenta e rápida (meios preconizados para o beneficiamento do leite) foi confirmada a presença de partículas virais infectantes tanto no leite Tipo-C quanto no queijo fresco e curado. Assim, os autores concluíram que estes produtos são potenciais transmissores do vírus o que acarreta em potencial risco a saúde humana. 
TRINDADE et al. (2006) encontraram duas cepas diferentes de VACV no mesmo animal durante um surto de varíola bovina no município de Guarani-MG no ano de 2006 (nomeados como GP1V e GP2V) que apresentavam grandes diferenças genéticas em suas regiões terminais. Os autores ainda sugerem que as cepas podem ter origens diferentes, sem descartar uma origem comum, e que através de sucessivas passagens por hospedeiros naturais o vírus tenha sofrido mutações e recombinações genéticas que originaram cepas diferentes.

BAXBY (1977), ao discorrer sobre o VACV, expõe que o mesmo foi amplamente utilizado para confecção de vacinas contra o VARV durante as campanhas mundiais de erradicação da varíola humana na década de 70, inclusive no Brasil. O que gera mais controvérsias entre os estudiosos sobre a origem do VACV; as principais hipóteses para o seu surgimento são: uma possível evolução do VARV em múltiplas passagens em humanos e no gado ou; uma recombinante entre o VARV e CPXV. Pouco se sabe sobre a origem do VACV no Brasil, a hipótese mais comumente aceita é que o vírus já circulava no país antes da campanha mundial de erradicação da varíola humana.

No final do século 20 e início do 21 , vários relatos de casos humanos de varíola bovina foram descritos nos estado de São Paulo, Minas Gerais, Rio de Janeiro e Goiás (SILVA et al., 2008; SANT'ANA et al., 2013).

\subsubsection{Poxvirose equina}

O Horsepox vírus (HSPV) é classicamente causador da poxvirose equina ou varíola equina, enfermidade esta que apresenta duas formas clínicas: uma benigna, a estomatite pustular contagiosa, que acomete o focinho e a cavidade oral e, a forma generalizada altamente contagiosa conhecida como estomatite papular equina. O HSPV também está associado a diversas dermatites exsudativas em equinos e difere clinicamente da Molluscum 
contagiosum e da doença Uasin Gish. Enquanto a primeira é uma enfermidade cutânea autolimitante, semelhante àquela provocada em humanos pelo vírus Molluscum contagiosum, a segunda é causada por um poxvírus pobremente caracterizado e sua ocorrência é restrita a equinos do noroeste da África (ESPARZA, 2013).

De acordo com ESPARZA (2013), os últimos relatos de ocorrência da varíola equina datam de 1970, na Mongólia e, esporadicamente, em alguns países do Continente Africano na década de 80. Desde 2012 a varíola equina está listada como doença de notificação obrigatória pela Organização Mundial de Saúde Animal, embora a doença seja considerada extinta (BRUM et al., 2010).

O HSPV tem alta semelhança filogenética com o VACV o que, de acordo com DELHON et al. (2006), sugerem que esse poderia ter originado o VACV. Outra hipótese é que o VACV tenha sido originado a partir de mutações genéticas ocorridas devido à transmissão do vírus de humanos vacinados durante as campanhas antivaríola humana para rebanhos de bovinos. 


\section{MATERIAIS E MÉTODOS}

\section{DELINEAMENTO EXPERIMENTAL}

O experimento foi conduzido conforme estudo randomizado ou experimental cujas hipóteses são: hipótese nula $\left(\mathrm{H}_{0}\right)$, o vírus iria replicar e os animais saudáveis irão desenvolver lesões macro e microscópicas compatíveis com a doença; e, a hipótese alternativa $\left(\mathrm{H}_{1}\right)$ de que o vírus não iria replicar e os animais não desenvolverão a enfermidade. Como o estudo não pretende fazer inferências sobre a prevalência da doença ou qualquer outra inferência populacional foi utilizada uma amostragem não probabilística por conveniência. Os dados obtidos a partir da avaliação do material biológico extraído foram classificados estatisticamente como variáveis qualitativas.

Para testar as hipóteses foram utilizados sete equinos machos, adultos, castrados, oriundos da tropa do regimento de Polícia Militar Montada do Distrito Federal (RPMon-DF). Os animais foram divididos em dois grupos de acordo com a cepa inoculada, designados segundo a fórmula: $\mathrm{C}_{\mathrm{x}} \mathrm{V}_{\mathrm{y}}$ ( da qual: $\mathrm{x}$ significa o número do animal e y a cepa viral inoculadaP1V ou P2V) e mais um animal controle (CNT). Os equinos foram alojados em baias individuais de aproximadamente $10 \mathrm{~m}^{2}$ no Hospital Veterinário de Grandes Animais da UnB (Hvet-UnB). As baias eram teladas para evitar a circulação de mosquitos e forradas com cama de palha de arroz. Os animais receberam alimentação diária de $8 \mathrm{~kg}$ de volumoso e $2 \mathrm{~kg}$ de concentrado divididos em duas refeições. O período total de experimentação foi de 28 dias a contar da data da inoculação (D0), excluídos os dias de aclimatação. 
Os animais permaneceram em jejum alimentar de 24 horas e, jejum hídrico de 12 horas, antes do dia da inoculação. No dia da inoculação, ou Odpi (dias pós inoculação), os animais foram sedados com cloridrato de xilazina $10 \%$ na dose de $1 \mathrm{mg} / \mathrm{kg}$ via intravenosa. Posteriormente, foram administrados $5 \mathrm{~mL}$ de lidocaína $2 \%$ sem vasoconstritor no forame infraorbital a fim de promover o bloqueio do nervo facial e obter a anestesia local da região nasal da face do animal. Uma região oval de aproximadamente $5 \mathrm{~cm}^{2}$ compreendida entre a comissura nasal lateral esquerda e a junção mucocutânea do lábio superior esquerdo (região nasolabial) foi padronizada para a inoculação do vírus; procedeu-se a limpeza e tricotomia da área e posterior escarificação da pele com uso de agulha estéril tamanho 40x12 mm. Com uso de pipetador automático foram inoculados aproximadamente $200 \mu \mathrm{L}$ de meio essencial mínimo que continham cerca de $10^{6,3} \mathrm{DICC}_{50} / \mathrm{ml}$ (dose infectante para $50 \%$ dos cultivos celulares). A região nasolabial direita também foi escarificada, onde foi aplicado o mesmo volume de meio de cultura sem o vírus, com o intuito de criar um controle negativo individual.

Diariamente a temperatura retal foi aferida e registrada e os locais de inoculação foram observados a fim de se verificar o início de desenvolvimento das lesões cutâneas. Amostras de sangue total, soro e suabe dos locais de inoculação foram coletadas nos dias $0,2,4,6,8$, $10,12,14,21$ e 28 dpi.

Amostras de sangue foram coletadas da veia jugular, após antissepsia do local com álcool $70 \%$. As amostras de sangue total foram aliquotadas em tubos de ensaio dos quais: 5 mL em tudo estéril com EDTA e, 30 mL em tubo seco para obtenção de soro. Após a coleta, os tubos secos foram mantidos em temperatura ambiente até completar a coagulação, as amostras foram centrifugadas a $5000 \mathrm{rpm}$ por 10' e o soro foi aliquotado em microtubos de 
1,5 mL. Os suabes foram armazenados em microtubos que continham meio de cultura para isolamento viral.

Todas as amostras foram imediatamente congeladas a $-70{ }^{\circ} \mathrm{C}$ por 20 dias após o término do experimento até serem enviadas ao Setor de Virologia da Universidade Federal de Santa Maria (UFSM), em Santa Maria- RS, onde foi realizado sorologia, isolamento viral e teste de reação em cadeia da polimerase (PCR). As amostras foram transportadas congeladas em caixa isotérmica. As alíquotas virais remanescente da inoculação (aproximadamente $100 \mu \mathrm{l})$ foram reenviadas para serem submetidas ao isolamento viral em cultivo celular a fim de se confirmar o título de partículas infectantes que foram inoculadas em cada animal.

Nos dias 4, 6, 8 e 10 dpi foram realizadas biópsias via punch de $6 \mathrm{~mm}$ que abrangiam parte da lesão e pele saudável. Para tanto, os animais foram sedados e anestesiados localmente com o mesmo protocolo utilizado para a inoculação. As amostras de pele foram coletadas e fixadas em solução tamponada de formol a $10 \%$ por 24 horas para posterior processamento histopatológico rotineiro no Laboratório de Patologia Veterinária da UnB (LPV-UnB) e coloração de hematoxilina- eosina (HE).

Após 28 dpi os animais foram submetidos à eutanásia com administração de acepromazina $1 \%$ na dose de $0,1 \mathrm{mg} / \mathrm{kg}$ e midazolam $0,5 \%, 0,2 \mathrm{mg} / \mathrm{kg}$ ambos intravenosos; indução anestésica com tiopental $5 \%, 5,0 \mathrm{mg} / \mathrm{kg}$, via intravenosa e o agente da eutanásia foi lidocaína $2 \%$ sem vaso constritor com volume total de $50 \mathrm{~mL}$, via intratecal na fossa magna.

Os animais foram então necropsiados e coletadas amostras de pele da região oronasal, fígado, rins, baço, linfonodos retrofaríngeos e mediastínicos, língua, pulmões, coração, estômago e intestinos delgado e grosso para fins de avaliação histopatológica. 
Foi realizada a limpeza e desinfecção diária das baias e do ambiente em que os animais tiveram acesso através de pulverização com solução de hipoclorito de sódio a $2 \%$ por meio de bomba de aspersão em volume médio diário de 15 L. Decorridos os 28 dias de experimento as baias foram higienizadas com solução de hipoclorito de sódio $2 \%$ e as camas incineradas. As baias permaneceram em quarentena de isolamento por 90 dias e, novamente pulverizadas com solução de hipoclorito antes de outros animais serem nelas alojados a fim de se reduzir ao máximo o risco de transmissão para outros animais.

\section{METODOLOGIA DE ANÁLISE DE AMOSTRAS}

Amostras de soro sanguíneo e suabe do local de inoculação foram testadas para soroconversão e excreção viral, respectivamente. O sangue total foi submetido à detecção de viremia através da PCR. Das amostras coletadas nos dias 2dpi e 6dpi foi realizado PCR para maior sensibilidade na detecção de DNA de partículas virais. Tais testes foram realizados em parceria com o Setor de Virologia do Departamento de Medicina Veterinária Preventiva da Universidade Federal de Santa Maria (UFSM-RS), de acordo com a metodologia descrita por CARGNELUTTI et al. (2012b). 


\section{RESULTADOS E DISCUSSÃO}

A distribuição temporal das lesões macroscópicas está resumida na Tabela 1.

Tabela 1: Distribuição temporal de lesões macroscópicas em equinos infectados experimentalmente pelo vírus Vaccinia e no animal controle (0 a 12 dpi)

\begin{tabular}{lllllllll}
\hline Animal & \multicolumn{7}{c}{ Dias Pós Inoculação } \\
\cline { 2 - 7 } & 0 & 2 & 4 & 6 & 8 & 10 & 12 \\
$\mathbf{C N T}$ & - & - & - & - & - & - & - \\
$\mathbf{C}_{1} \mathbf{V}_{1}$ & - & - & + & + & - & - & - \\
$\mathbf{C}_{2} \mathbf{V}_{2}$ & - & + & + & + & + & - & - \\
$\mathbf{C}_{3} \mathbf{V}_{1}$ & - & - & + & + & - & - & - \\
$\mathbf{C}_{4} \mathbf{V}_{2}$ & - & - & - & - & - & - & - \\
$\mathbf{C}_{5} \mathbf{V}_{1}$ & - & - & - & - & - & - & - \\
$\mathbf{C}_{6} \mathbf{V}_{2}$ & - & - & + & + & - & - & -
\end{tabular}

Legenda: '+'- presença de alterações macroscópicas; '-'- ausência de alterações macroscópicas; CNTAnimal Controle, $\mathrm{C}_{1} \mathrm{~V}_{1^{-}}$Cavalo 1 inoculado com P1V, $\mathrm{C}_{2} \mathrm{~V}_{2^{-}}$Cavalo 2 inoculado com P2V, $\mathrm{C}_{3} \mathrm{~V}_{1^{-}}$Cavalo 3 inoculado com P1V, $\mathrm{C}_{4} \mathrm{~V}_{2^{-}}$Cavalo 4 inoculado com $\mathrm{P} 2 \mathrm{~V}, \mathrm{C}_{5} \mathrm{~V}_{1^{-}}$Cavalo 5 inoculado com $\mathrm{P} 1 \mathrm{~V}, \mathrm{C}_{6} \mathrm{~V}_{2^{-}}$Cavalo 6 inoculado com P2V.

A evolução cronológica das lesões macroscópicas está ilustrada na Fig. 1 (A-D). Em 2dpi, o equino $\mathrm{C}_{2} \mathrm{~V}_{2}$, apresentou pápulas que variavam de 5 a $10 \mathrm{~mm}$ de diâmetro, com centro deprimido ou ulcerado e bordos levemente elevados na junção mucocutânea do lábio superior esquerdo. Com 4dpi esse mesmo animal apresentou lesão ulcerativa, crostosa e proliferativa, focal, discreta de aproximadamente $0,8 \mathrm{~cm}$ de diâmetro abaixo da narina esquerda (Fig. 1B). No mesmo dia, o equino $\mathrm{C}_{1} \mathrm{~V}_{1}$ apresentou lesão semelhante de aproximadamente $0,5 \mathrm{~cm}$ de 
diâmetro na narina esquerda e úlcera na mucosa do lábio inferior esquerdo de aproximadamente $1 \mathrm{~cm}$ de diâmetro. As lesões em $\mathrm{C}_{1} \mathrm{~V}_{1}$ regrediram e, em dois dias, já não eram mais observados traços das mesmas.

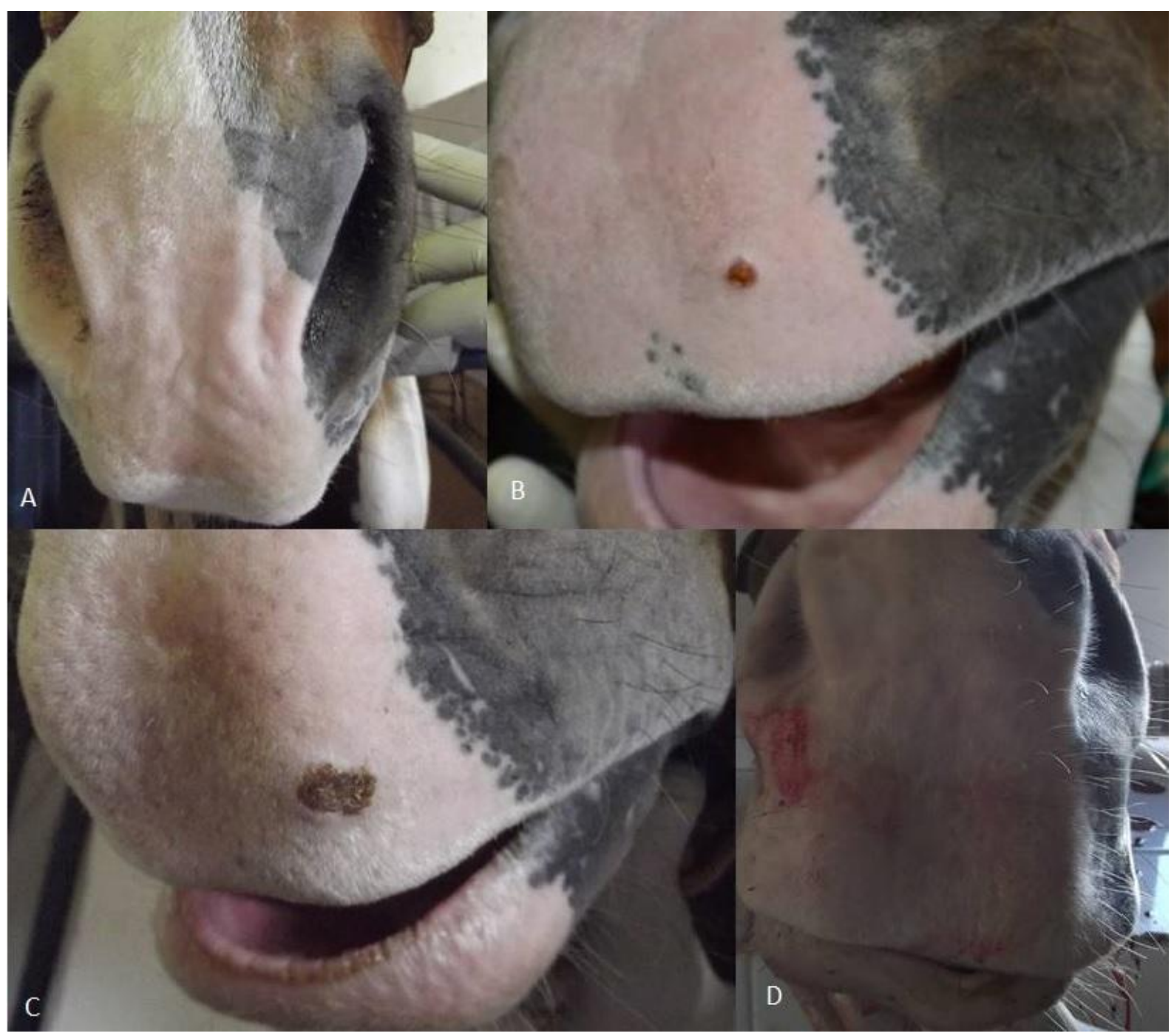

Figura 1- Evolução cronológica das lesões macroscópicas de equino $\left(\mathrm{C}_{2} \mathrm{~V}_{2}\right)$ infectado experimentalmente com vírus Vaccinia. A- em 0dpi. B- em 4dpi, nota-se lesão ulcerativa, proliferativa, crostrosa, focal e discreta na região parassagital-rostral ao lábio superior esquerdo. C- em 6 dpi, nota-se a persistência e evolução da lesão para área focalmente extensa de lesão crostrosa e proliferativa. D- 28 dpi, nota-se ausência de lesões macroscópicas nas áreas de inoculação.

Com 5dpi, os animais $\mathrm{C}_{3} \mathrm{~V}_{1}$ e $\mathrm{C}_{6} \mathrm{~V}_{2}$ apresentaram os primeiros sinais, que incluíram úlcera focal discreta, de aproximadamente $0,3 \mathrm{~cm}$ de diâmetro, próxima à comissura nasal lateral 
esquerda e outra no lábio superior esquerdo, respectivamente. Em 7dpi não foram mais observadas quaisquer lesões macroscópicas nesses animais.

Até 8dpi as lesões macroscópicas persistiram apenas no animal $\mathrm{C}_{2} \mathrm{~V}_{2}$, com crostas e secreção serosa no local do punch. No dia 10dpi já não eram mais visíveis quaisquer lesões nos locais de inoculação ou em áreas adjacentes.

Os animais $\mathrm{C}_{4} \mathrm{~V}_{2}$ e $\mathrm{C}_{5} \mathrm{~V}_{1}$ não apresentaram lesões macroscópicas nos locais de inoculação ou em áreas adjacentes durante os 28 dias do período experimental. Como já era esperado nenhum equino desenvolveu lesão no plano nasal direito.

Portanto, neste estudo observou-se lesões macroscópicas entre 2 e 8 dpi, com duração média de quatro dias, sem o surgimento de novas lesões até o fim do estudo. Este período de observação das lesões foi mais curto do que aquele descrito por BRUM et al. (2010) que observaram curso clínico de 6 a 12 dias, desde o surgimento dos primeiros sinais, a saber: pápulas intradermais puntiformes, de 2 a $3 \mathrm{~mm}$ de diâmetro, no focinho e próximo às narinas e face interna dos lábios. No presente estudo, os animais desenvolveram lesões compatíveis com a fase aguda da doença.

Os achados macroscópicos do presente estudo diferem daqueles obtidos por STUDDERT (1989) que, ao conduzir infecção experimental com VACV em equinos, observou o surgimento das primeiras lesões em 4dpi caracterizadas por pústulas de 2 a $4 \mathrm{~mm}$ com centro hemorrágico e distribuição multifocal a coalescente severa. O mesmo autor descreve ainda que em 22dpi já eram visíveis cicatrizes nas regiões de inoculação nos três animais testados. É possível que STUDDERT (1989) tenha usado cepa de VACV mais virulenta quando comparado com as cepas utilizadas no presente estudo, explicando desta forma a maior severidade das lesões no estudo conduzido por este autor. 
FERREIRA et al. (2008), ao trabalharem com inoculação intranasal de VACV em camundongos, observaram que todos os animais apresentaram os primeiros sinais da infecção a partir de 2dpi. Já CARGNELUTTI et al. (2012b) infectaram experimentalmente coelhos com as mesmas cepas virais testadas no presente estudo e observaram o desenvolvimento de lesões a partir de 1dpi, caracterizadas por hiperemia, máculas, pápulas, vesículas e úlceras com secreção serossanguinolenta e proliferação multifocal a coalescente nas áreas adjacentes. Após 30dpi alguns animais ainda apresentavam cicatrizes. Neste mesmo estudo, o grupo experimental que foi tratado com uma associação das duas cepas $(\mathrm{P} 1 \mathrm{~V}+\mathrm{P} 2 \mathrm{~V})$ apresentaram sinais locais e sistêmicos mais severos do que os grupos tratados com as cepas isoladamente, além de desenvolverem infecções secundárias caracterizadas por secreção purulenta. Tais resultados apontam que, do ponto de vista clínico, a coinfecção dos animais com as duas cepas é mais severa.

Em um estudo sobre a patogenicidade do VACV em bovinos, oito vacas leiteiras foram inoculadas com a cepa GP2V via escarificação epidermal nas tetas anteriores (RIVETTI JR et al., 2012). Esses autores relatam que todos os animais desenvolveram lesões compatíveis com aquelas já descritas a partir de 2dpi com cura em 18 dias. Entretanto, ainda não foram realizados estudos que demonstrem a patogenicidade da infecção natural ou experimental em bovinos com as cepas P1V e P2V.

A evolução cronológica das lesões microscópicas está ilustrada na Fig. 2 (A-D). Em 4dpi foram observadas, nas biópsias das regiões de inoculação dos animais $C_{1} V_{1}$ e $C_{2} V_{2}$, hiperplasia da epiderme (acantose), acantólise multifocal discreta e hiperqueratose focal moderada, com perda focalmente extensa das camadas da epiderme (úlcera) e necrose focalmente extensa com agregados intralesionais de bactérias cocóides basofílicas (Fig. 2A e 2C). Havia ainda degeneração hidrópica focalmente extensa moderada. Na derme superficial 
havia infiltrado focalmente extenso com acentuada quantidade de neutrófilos íntegros e degenerados, e menor quantidade de macrófagos e linfócitos. $\mathrm{O}$ animal $\mathrm{C}_{2} \mathrm{~V}_{2}$ apresentou alterações mais acentuadas e formação de vesículas intradérmicas. Inclusões eosinofílicas intracitoplasmáticas foram infrequentemente observadas em queratinónocitos degenerados adjacentes às áreas de necrose neste mesmo equino (Fig. 2B).

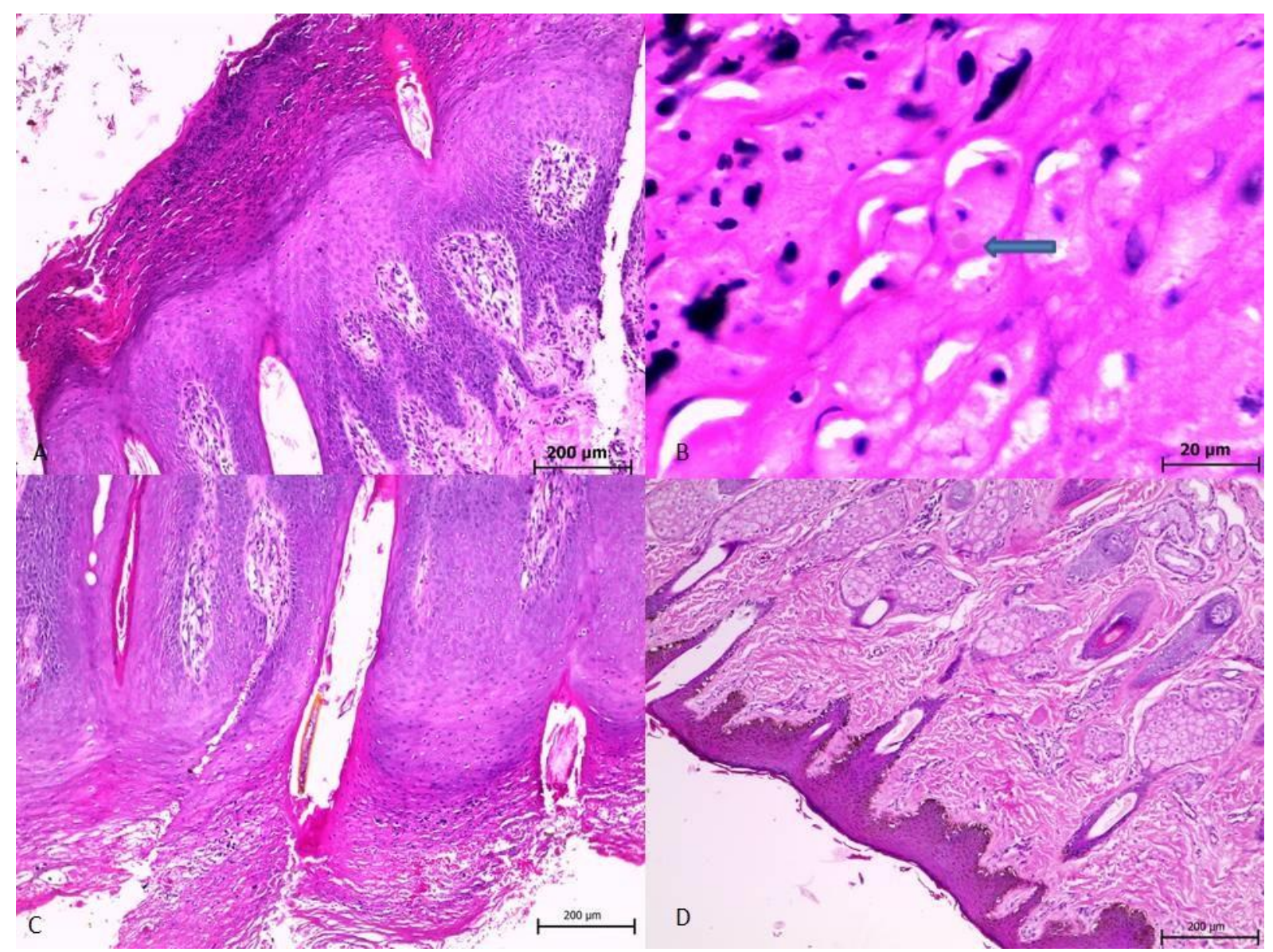

Figura 2- Pele (região nasolabial esquerdo) de equino $\mathrm{C}_{2} \mathrm{~V}_{2}$ infectado experimentalmente pelo vírus Vaccinia (VACV). A- em 4 dpi, nota-se lesão crostrosa, com hiperqueratose paraqueratótica e acantose. B- mesma região em maior aumento, destaque para inclusão viral eosinofílica intracitoplasmática (seta). C- em 6 dpi, nota-se lesão crostrosa e proliferativa com hiperqueratose e degeneração balonosa de queratinócitos. D- em 28 dpi, nota-se ausência de lesões compatíveis com aquelas causadas pelo VACV. HE. 
Em 6dpi o animal $\mathrm{C}_{6} \mathrm{~V}_{2}$ apresentou área focalmente extensa moderada de crosta associada a degeneração hidrópica moderada de queratinócitos. No mesmo dia, o animal $\mathrm{C}_{3} \mathrm{~V}_{1}$ não apresentava quaisquer alterações microscópicas.

Já em 8dpi os animais $\mathrm{C}_{1} \mathrm{~V}_{1}$ e $\mathrm{C}_{2} \mathrm{~V}_{2}$ apresentaram crosta focal discreta com úlcera discreta e infiltrado moderado de neutrófilos íntegros e degenerados, macrófagos e linfócitos. Em 10dpi os cavalos $\mathrm{C}_{4} \mathrm{~V}_{2}$ e $\mathrm{C}_{5} \mathrm{~V}_{1}$ não apresentaram quaisquer lesões microscópicas. As amostras coletadas aos 28 dpi de todos os órgãos de todos os equinos não apresentaram alterações macro ou microscópicas (Fig. 2D).

Tais achados microscópicos estão de acordo com aqueles descritos por STUDDERT (1989), no entanto diferem apenas em intensidade já que as alterações observadas por este pesquisador foram mais severas, tanto macro, quanto microscopicamente. A menor intensidade das alterações observadas no presente estudo pode dever-se à diferença genética entre as cepas de VACV utilizadas nos dois estudos.

CARGNELUTTI et al. (2012a), em um estudo que utilizou as mesmas cepas virais de VACV (P1V e P2V) em coelhos, observaram as alterações microscópicas mais intensas nos locais de inoculação, além de pneumonia intersticial difusa severa e hiperplasia epitelial bronquiolar. Tal comparação sustenta a hipótese sugerida no presente estudo de que os equinos são menos susceptíveis às infecções provocadas pelas cepas P1V e P2V, em comparação às outras espécies comprovadamente sensíveis.

Os resultados das análises sorológicas e de excreção viral estão agrupados na tabela 2. 
Tabela 2: Resultados dos testes de sorologia por soroneutralização e excreção viral (isolamento em cultivo celular e PCR) de equinos infectados experimentalmente pelo vírus Vaccinia.

\begin{tabular}{|c|c|c|c|c|c|c|c|c|c|c|c|c|c|c|}
\hline \multirow[t]{3}{*}{ Animais } & \multicolumn{2}{|c|}{ Sorologia } & \multicolumn{6}{|c|}{ Excreção viral: isolamento viral } & \multicolumn{6}{|c|}{ Excreção viral: PCR } \\
\hline & & & 2dpi & 4dpi & 6dpi & 8dpi & 10dpi & 12dpi & 2 dpi & 4dpi & 6dpi & 8dpi & 10dpi & 12dpi \\
\hline & 0 & & & & & & & & & & & & & \\
\hline CNT & $<2$ & $<2$ & - & - & - & - & - & - & - & - & - & - & - & - \\
\hline C1V1 & $<2$ & $<2$ & - & - & - & - & - & - & - & - & - & - & - & - \\
\hline $\mathrm{C2V} 2$ & $<2$ & $<2$ & - & + & + & + & - & - & - & + & + & + & - & - \\
\hline C3V1 & $<2$ & $<2$ & - & - & - & - & - & - & - & - & - & - & - & - \\
\hline C4V2 & $<2$ & $<2$ & - & - & - & - & - & - & - & - & - & - & - & - \\
\hline C5V1 & $<2$ & $<2$ & - & - & - & - & - & - & - & - & - & - & - & - \\
\hline C6V2 & $<2$ & $<2$ & - & - & - & - & - & - & - & - & - & - & - & - \\
\hline
\end{tabular}

Legenda: '+' dias que foram observados resultados positivos; '-' dias em que foram observados resultados negativos.

Apenas o cavalo $\mathrm{C} 2 \mathrm{~V} 2$ apresentou resultados positivos para excreção viral nos suabes dos dias 4, 6 e 8 dpi. Este resultado pode ter ocorrido em razão do desenvolvimento da infecção/lesão ter sido muito discreta e consequentemente com mínima replicação e, consequente excreção viral, resultando desta forma em baixa detecção de vírus infeccioso. Embora a replicação viral tenha sido discreta nos animais infectados, a titulação das alíquotas remanescentes da inoculação viral comprovou a presença de partículas virais infectantes em quantidade suficiente (106,3DICC50/ml) no momento da inoculação. Este resultado garante que os animais foram adequadamente expostos às cepas P1V e P2V. 
Em um estudo realizado por pesquisadores do Setor de Virologia da UFSM, em

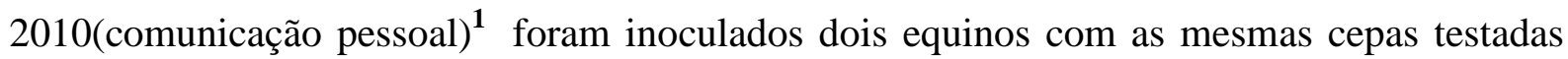
no presente estudo via escarificação do plano nasolabial. A quantidade de partículas infectantes inoculadas foi de aproximadamente $10^{6,3} \mathrm{DICC}_{50} / \mathrm{ml}$, sendo que os animais foram acompanhados durante 15 dias. Neste período foram realizados suabes do local de inoculação, sorologia e avaliação macroscópica. No entanto, não foram detectadas lesões macroscópicas, excreção viral ou sorologia positiva. Estes resultados corroboram com a hipótese de que as cepas P1V e P2V são de baixa virulência para equinos saudáveis.

Em ambos os experimentos, com as cepas P1V e P2V, foram inoculados equinos aparentemente hígidos e sem histórico clínico de situação que pudesse ter comprometido o estado imunológico geral dos animais. Entretanto, essas cepas foram isoladas de animais que se encontram em situação de estresse no surto relatado por BRUM et al. (2010). A maioria dos animais afetados eram éguas recém-paridas e potros que se encontravam aglomerados em um ambiente fechado. Desta forma, é provável que a maior severidade das lesões no surto natural se deva ao estado imunológico fragilizado dos equinos.

CAMPOS et al. (2010), confirmaram que P1V e P2V diferem geneticamente entre si por volta de $5 \%$ nos genes analisados, sendo que foram originalmente isoladas do mesmo animal durante o surto; desta forma, além da imunossupressão dos animais naturalmente infectados, a gravidade da infecção nesses animais pode estar relacionada à coinfecção com as duas cepas.

\footnotetext{
${ }^{1}$ Informações cedidas por Juliana Felipetto Cargnelutti- Setor de Virologia da UFSM, março de 2014.
} 


\section{CONSIDERAÇÕES FINAIS}

Este estudo parece ser o primeiro a demonstrar, ainda que de forma branda, a infecção experimental em equinos pelo vírus Vaccinia, cepas P1V e P2V no Brasil, com desenvolvimento de lesões macro e microscópicas.

O estado imunológico dos animais e a virulência do vírus podem estar associados com os achados discretos apresentados neste trabalho bem como a coinfecção ocorrida no surto natural, não realizada no presente estudo.

Portanto, estudos experimentais da infecção em equinos imunossuprimidos e coinfecção com o P1V e P2V em equinos sadios seriam fundamentais para responder questões importantes para o melhor entendimento da patogenia do VACV em equinos. Adicionalmente, como não há descrições da infecção em bovinos com estas cepas, seria importante a realização de estudos experimentais em bovinos utilizando as mesmas para avaliar a patogenicidade destes isolados nessa espécie. 


\section{REFERÊNCIAS BIBLIOGRÁFICAS}

ABRAHÃO, J. S.; SILVA-FERNANDES, A. T.; ASSIS, F. L. et al. Human vaccinia virus and pseudocowpox virus co-infection: clinical description and phylogenetic characterization. Journal of Clinical Virology, v. 48, p. 69-72, 2010.

BAXBY, D. The origins of vaccinia virus. Journal of Infectious Disease, v. 136, p. 453$455,1977$.

BRUM, M. C. S.; ANJOS, B. L.; NOGUEIRA, C. E. W. et al. An outbreak of orthopoxvirusassociated disease in horses in southern Brazil. Journal of Veterinary Diagnostic Investigation, v. 22, p. 143-147, 2010.

CAMPOS, R. K.; BRUM, M. C. S.; NOGUEIRA, C. E. W. et al. Assessing the variability of brazilian vaccinia virus isolates from a horse exanthematic lesion: coinfection with distinct viruses. Archives of Virology, p. ., 2010

CARGNELUTTI, J. F.; SCHMIDT, C.; MASUDA, E. K. et al. Vaccinia viruses isolated from skin infection in horses produced cutaneous and systemic disease in experimentally infected rabbits. Research in Veterinary Science. v. 93, p. 1070-1075, 2012a.

CARGNELUTTI, J. F.; SCHMIDT, C.; MASUDA, E. K. et al. Vaccinia viruses isolated from cutaneous disease in horses are highly virulent for rabbits. Microbial Pathogenesis, v. 52, p. 192-199, 2012b. 
DAMON, I. Poxviridae and their replication. In: KNIPE, D. M.; HOWLEY, P. M.; GRIFFIN, D. E.; LAMB, R. A.; MARTIN, M. A.; ROIZMAN, B.; STRAUS, S. E.; Fields Virology, New York: Raven Press, 2007. p. 2079-2081.

DELHON, G. A.; AFONSO, C. L.; LU, Z.; ZSAK, L.; SANDYBAEV, N. T. Genome of horsepox virus. Journal of Virology, v. 80, p. 9244-9258, 2006.

ESSBAUER, S.; PFEFFER, M.; MEYER, H. Zoonotic poxviruses. Veterinary Microbiology, v. 140, p. 229-236, 2010.

ESPARZA, J. Has horsepox become extinct? Veterinary Record, p. 272-273, 2013.

FERREIRA, J. M. S.; ABRAHÃO, J. S.; DRUMOND, B. P. et al. Vaccinia virus: shedding and horizontal transmission in a murine model. Journal of General Virology, v. 89, p. 29862991, 2008.

FLORES, E. F. Virologia Veterinária. Santa Maria: Editora UFSM, 2007. 888p.

KAMINJOLO JR, J.S; JOHNSON, L.W.; FRANK, H.; GICHO, J.N. Vaccinia-like pox vírus identified in a horse with a skin disease. Zentralbl Veterinarmed B, v. 21, p. 202-206, 1974.

LEITE, F. A.; DRUMOND, B. P.; TRINDADE, G. S. et al. Passatempo virus, a vaccinia virus strain, Brazil. Emerging Infectious Diseases, v. 11, p. 1935-1938, 2005.

LOBATO, Z. I. P.; TRINDADE, G. S.; FROIS, M. C. M. et al. Surto de varíola bovina causada pelo vírus vaccinia na região da zona da mata mineira. Arquivo Brasileiro de Medicina Veterinária e Zootecnia, v. 57, p. 423-429, 2005. 
LUDOULFO DE OLIVEIRA, T. M. Vaccinia vírus isolado de bovinos: sensibilidade a desinfetantes e viabilidade no leite e derivados. Belo Horizonte: Universidade Federal de Minas Gerais, 2009. 76p. Dissertação de Mestrado em Ciência Animal.

LUDOULFO DE OLIVEIRA,T. M.; REHFELD,L. S.; SIQUEIRA, J. M. F. et al. Vaccinia virus is not inactivated after thermal treatment and cheese production using experimentally contaminated milk. Foodborne Pathogens And Disease, v. 7, p. 1491-1496, 2010.

PERES, M. G. Fatores de risco e prevalência de animais domésticos e silvestres portadores de anticorpos contra Vaccinia Vírus na região centro oeste do estado de São Paulo. Botucatu: Universidade Estadual de São Paulo, 2012. 54p. Dissertação de Mestrado.

RIVETTI JR, A. V.; GUEDES, M. I. M. C.; REHFELD, I. S. et al. Bovine vaccínia, a sistematic infection: evidence of a fecal shedding, viremia and detection in lymphoid organs. Veterinary Microbiology, v. 162, p. 103-111, 2012.

SANT'ANA, F. J. F.; LEAL, A. A.; RABELO, R. E. et al. Outbreaks of vesicular disease caused by Vaccinia virus in dairy cattle from Goiás State, Brazil (2010-2012). Pesquisa Veterinária Brasileira, v. 33, p. 860-866, 2013.

SILVA, A. C.; REIS, B. B.; JUNIOR, J. E. R. R. et al. Infecção em humanos por varíola bovina na microrregião de Itajubá, estado de Minas Gerais: relato de caso. Revista da Sociedade Brasileira de Medicina Tropical, v. 41, p. 507-511, 2008.

SILVA-FERNANDES, A. T.; TRAVASSOS, C. E. F.; FERREIRA, J. M. S. et al. Natural human infections with vaccinia virus during bovine vaccinia outbreaks. Journal of Clinical Virology, v. 44, p. 308-313, 2009.

STUDDERT, M. J. Experimental vaccínia virus infection of horses. Australian Veterinary Journal, v. 66, p. 157-158, 1989. 
TRINDADE, G. S.; FONSECA, F. G.; MARQUES, J. T. et al. Belo Horizonte virus: a vaccinia-like virus lacking the A-type inclusion body gene isolated from infected mice. Journal of General Virology, v. 85, p. 2015-2021, 2004.

TRINDADE, G. S.; LOBATO, Z. I. P.; DRUMOND, B. P. et al. Short Report: isolation of two vaccinia virus strains from a single bovine vaccinia outbreak in rural area from brazil: implications on the emergence of zoonotic orthopoxviruses. The American Society of Tropical Medicine and Hygiene, v. 75, p. 486-490, 2006. 
ANEXO 1

CERTIFICADO DE APROVAÇÃO DO COMITÊ DE ÉTICA NO USO DE ANIMAIS

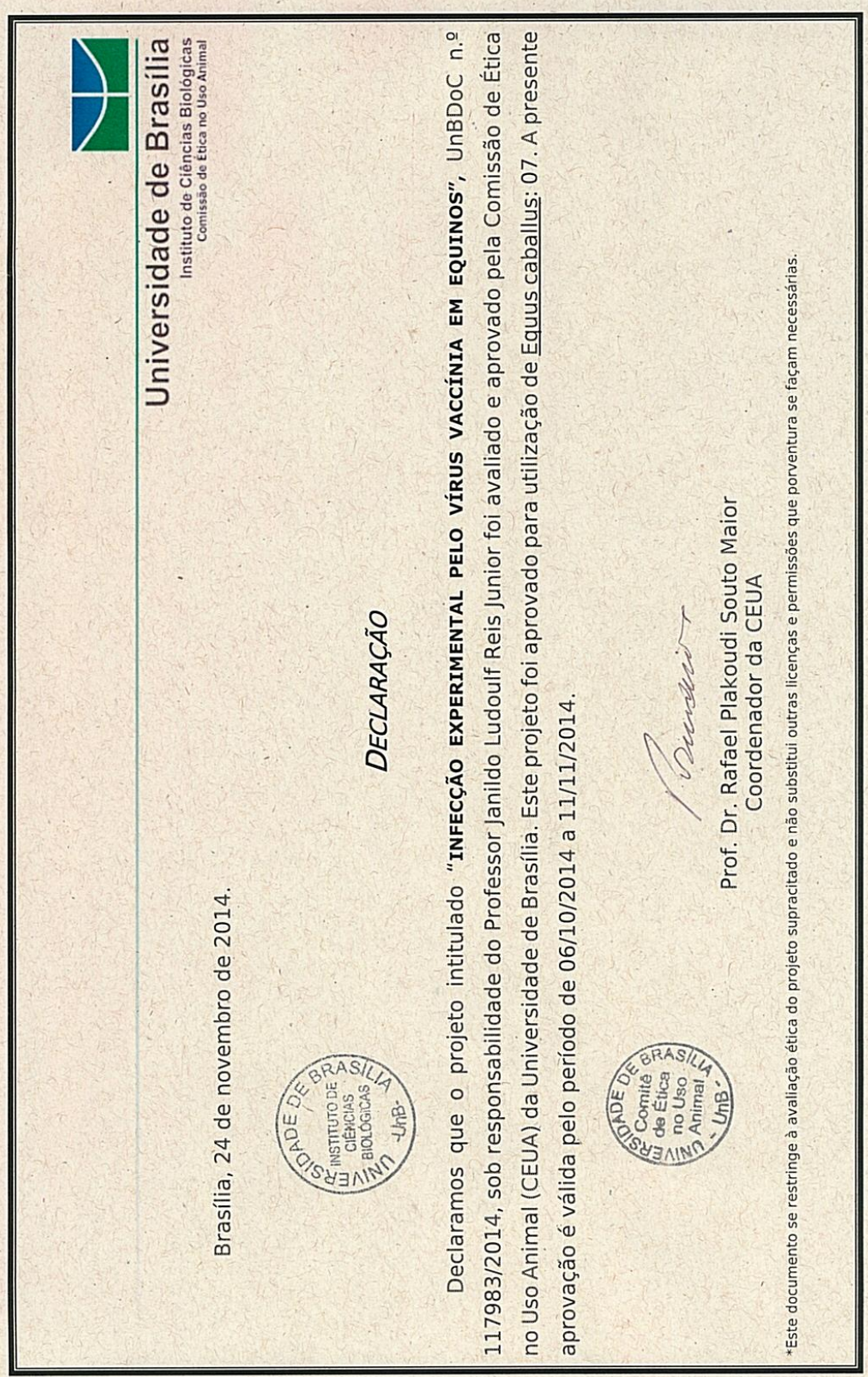

